\title{
EXPERIENCIA HUMANA Y MESTIZAJE CULTURAL EN LA SOCIEDAD DE LA INFORMACIÓN
}

\author{
Joaquín García Carrasco \\ Catedrático de Pedagogía \\ Universidad de Salamanca
}

\author{
Recibido 16-III-2004 • Aceptado 11-V-2004
}

Resumen: En la movilidad espacial de las personas y las creaciones culturales se instauran las condiciones para el fenómeno del mestizaje. Cada día parece más evidente la importancia de contenidos, actitudes y valores, calificados de "transversales" en el currículo. Entre ellas, se encuentra la denominada "Educación Intercultural". Esa transversalidad se nutre, precisamente, de los elementos fundamentales de las que Henri van Leer denominaba "las humanidades del siglo XX”. En la actualidad, tres procesos sociales están revitalizando el problema: los movimientos migratorios y sus consecuencias sociales, el florecimiento de los nacionalismos, los atrincheramientos culturales y la sedicente aparición de un mundo nuevo hecho de información que, a semejanza de un agujero negro, todo parece absorberlo en una globalidad inédita de pensamiento único. En esta situación de contacto intercultural generalizado, el fomento de la mentalidad pluralista y abierta se convierte en una meta de formación básica. Para el cultivo de esa mentalidad se proponen organizadores de contenidos, marcos para el fomento de actitudes, criterios para construir estrategias, posiciones desde las que descubrir el valor del entendimiento social entre ciudadanos diferentes.

Palabras clave: Mestizaje, Educación Intercultural, Cultura, Pluralidad Cultural.

\section{Introducción}

Recientes acontecimientos históricos conflictivos están incitando, tanto en medios de comunicación como en las conversaciones, a replantear y hacer evidente los términos con los que se explicita la representación de la cultura, la concepción de la identidad cultural, las decisiones sobre modos de afiliación ideológica y orientación de prácticas convivenciales en contextos culturales plurales. Las actitudes varían desde planteamientos de confrontación-segregación a los de solidaridad-integración. Aun cuando el conflicto puntual exaspera el problema y aumenta la urgencia de la decisión, la permanente presencia de las diferencias está transformando el espacio de proximidad, el de la referencia identitaria, en una encrucijada de flujos constantes de alteridades y extrañezas, en un ágora de interculturalidad. La hospitalidad para con esta situación, desestabiliza el equilibrio entre supuestos iguales y agrieta la imagen de una cultura con ilusoria pureza de estirpe. La incorporación reflexiva a las situaciones culturalmente plurales induce renovación en la sensibilidad respecto a vínculos y afiliaciones, incita a reconstruir la representación de la identidad y promueve responsabilidades en las acciones de formación. Este trabajo pretende justificar el beneficio pedagógico de una aproximación cultural que muestre, 


\begin{abstract}
Both spatial mobility and change of settlements embody the necessary conditions for crossbreeding (mestizaje). Day after day, the relevance of the contents, proceedings, attitudes and values of the so -called "cross-cutting" subjects in the curricula seem more obvious, among them, "Intercultural Education". This "cross-cutting" nature nurtures itself precisely from the fundamental elements that Henri van der Leer called "twentieth-century humanities". Nowadays, three social processes are revitalizing the problem: migration movements and their consequences, the flourishing of nationalism and cultural entrenchments and the self-asserted appearance of a new world made up of information that, similar to a black hole, seems to absorb everything in a hitherto unheard of globalization. In this situation of generalized intercultural contact, the encouragement of a plural and open mentality becomes a basic education goal. To develop that mentality I propose six content organizers, six frames to foster attitudes, six criteria on which to build strategies, positions from which the value of social understanding among different citizens can be unraveled.
\end{abstract}

Key words: Crossbreeding, Itercultural Education, Culture, Cultural Plurality. desde el principio, que la irrepetibilidad de cada historia experiencial humana (contexto subjetivo), siempre tiene lugar en un entorno social marcado por diferencias de todo tipo (contexto intersubjetivo), dentro de un marco de referencia cultural esencialmente mestizo (contexto objetivo). La oportunidad de encontrar esta verdad es planteada por las consecuencias socioculturales de los movimientos migratorios y los masivos intercambios de información. La perspectiva intercultural se convierte, por estos motivos, en objetivo y meta de los procesos de formación. Este trabajo pretende mostrar la importancia de tomar la advertencia del mestizaje cultural como contexto para el desarrollo de la formación en contextos culturalmente plurales, para el fomento de sentimientos y actitudes de tolerancia, para el fomento de prácticas sociales solidarias y para dinámicas convivenciales de integración.

\section{La interculturalidad venía siendo prevista en las Normas Fundamentales de los Sistemas Sociales}

Hace unos años plantear el tema de una "educación intercultural", aunque había bastantes pedagogos que lo traían a colación, parecía cuestión sin perentoria necesidad. La "Ley Orgánica de Ordenación del Sistema Educativo" español, por ejemplo, en su preámbulo, sin mención explícita del término, indica que la formación tiene como meta favorecer en los jóvenes "su propia y personal identidad". Identidad que, al mostrarse socialmente, se traduce en ejercicio de "la libertad, la tolerancia y la solidaridad", ..."de manera crítica y en una sociedad axiológicamente plural"1.

Independientemente de la cultura que se considere e independientemente de la manera en la que se ejerzan las responsabilidades de formación por parte de los agentes que las asumen, "la selección de 
los contenidos, la prioridad que establecen los mismos, las actividades del programa, las teorías en que basa su actividad pedagógica, la visión de su función como profesor,..., no escapan a la influencia del sistema de valores que sustenta" la comunidad social culturalmente dominante (Ortega, P.-Minguez, R.-Gil, R., 1996, p. 9). Los mismos valores que contiene el patrimonio cultural que identifica a una comunidad (cultura real) son los que inspiran y se entreveran en el proceso de transmisión e incorporación cultural (cultura personal). "En una civilización como la nuestra, en la que la lucha por la vida sólo permite sobrevivir a los técnica y socialmente diestros, es una pregunta anterior a otra...., la de si creemos en serio que merece la pena, a pesar de todo, enseñar a apreciar aquellos valores por los que pareció luchar la Modernidad: la libertad, la igualdad, la solidaridad o la imparcialidad" (A. Cortina, 1993) ${ }^{2}$.

Esos mismos valores, en opinión de $\mathrm{K}$. Popper (1982) son los que caracterizan a las sociedades "abiertas" y los que las distinguen de sus enemigos; para el autor, esos valores se nombran como, racionalismo crítico, libertad individual y tolerancia. Las sociedades abiertas, que encarnan esos valores, y los modos personales de ser social en los que esos valores son principios activos, presentan total consanguinidad. Las sociedades abiertas son sociedades que se sienten plurales, "el código genético de la sociedad abierta es el pluralismo. Porque es el pluralismo el que descifra mejor que cualquier otro concepto las creencias de valor y los mecanismos que han producido históricamente la sociedad libre y la ciudad liberal y por ello el que mejor permite precisar y profundizar las "aperturas" que vamos a debatir" (Sartori, 2001, p. 15). Los individuos abiertos son aquellos que traducen en sentimientos y en principios comportamentalmente activos, sentimientos y principios morales, aquellos valores que inspiraron la modernización, la humanización de la Sociedad.
En resumen, no podemos plantear un proceso de formación sin confrontarlo con un sistema de valores, entre los valores fundamentales se encuentran aquellos que vertebran la convivencia. La modernidad entendió que tal vertebración no podía tener lugar sin la conciencia de la pluralidad cultural. No podrá haber, pues, calidad en el proceso de formación si su contexto no es intercultural. La interculturalidad constituye el marco referencial del proceso de socialización en la contemporaneidad y la conciencia de mestizaje cultural creemos que es el fundamento de las actitudes de tolerancia y de mentalidad pluralista. Creemos que la interculturalidad empieza por tomar conciencia de la dinámica de intercambio que constituye esencialmente a la cultura.

Este ideario se proclama en los lugares axiológicos de las constituciones, en los capítulos cardinales de la ética mínima para el mantenimiento coherente de la humanidad diversa, en los criterios fundamentales para dirimir conflictos en las sociedades democráticas y configura tal vez el único elemento verdaderamente ecuménico que comparten las propuestas no dogmáticas de las religiones con más raigambre y tradición.

\section{La convivencia de una ciudadanía intercultural es objetivo del proceso de unificación europea}

$\mathrm{Y}$ este ideario es el que se somete a prueba, en este momento, en el entorno europeo, al menos por dos series de contingencias que nos exigen a todos reflexión y compromiso. No se trata de una prueba meramente abstracta, cuyo desenlace tenga lugar en una confrontación de argumentos. La prueba real tiene lugar, p.e. en el Continente Europeo, en el propio espacio social de convivencia. Las dos contingencias, a las que nos referimos en este texto, son los movimientos migratorios hacia y en 
la Europa geográfica y el propio proceso de integración de la Unión Europea ${ }^{3}$. No se trata de sucesos o acontecimientos puntuales, sino de procesos con una fuerte potencia transformadora de los factores que mantenían el equilibrio cultural del espacio social europeo, en sus particularidades regionales y en su conjunto, como proyecto de integración; por estos motivos los denominamos contingencias. Sus efectos son observables en el corto plazo (moneda única $\mathrm{y}$, al mismo tiempo, conflictos de integración social, política o cultural) y en el largo plazo (integración política, transformación del sistema simbólico, cambios en la referencia espacial de la identidad, cambios de escala en la referencia cultural...). El proyecto de integración económica arrancó primero y alcanzó un hito con la moneda única, más lento y empinado se muestra el camino que lleva a la unión política, quién llegará a ver los primeros relieves de un espacio europeo de armonización cultural. Muchos estiman que en esa dirección se orienta la institucionalización de un espacio común de organización académica universitaria, el contenido de la Declaración de Bolonia.

¿Convivir en democracia, tolerancia y solidaridad con libertad de movimiento y de asentamiento? Esto no se expresa cualitativamente en términos de globalización, como si se tratara de un "grafo" sin diferencias culturales; más bien tiende a reclamar aquellos ideales de la modernidad, aludidos anteriormente, y a promover una práctica que permita la convivencia por adaptación cualitativa a la diferencia. Este recorrido es muy largo, es multidimensional y, es de prever, que nunca estemos todos acomodados a todas las variantes situacionales posibles. Un simple patrón indumentario, por la forma de defenderlo y por la manera de interpretarlo, puede transformarse en un conflicto de principios fundamentales. Ha ocurrido primero en Francia y luego en España con el velo de las jóvenes islámicas que pretendían asistir a clase con este tipo de tocado.
Tal vez, la propia Europa constituye el argumento de que, para que todos los hombres puedan disfrutar la libertad de movimiento y de asentamiento, tendrían que cambiar los criterios económicos y los modos de relación entre todas las comunidades humanas. Los primeros pasos de la Unión Europea asumieron criterios económicos de cohesión y solidaridad. Desde el punto de vista de los que tienen mayor "calidad de vida" esto, con todos, es una utopía, y blindan sus fronteras; desde el punto de vista de los "náufragos del desarrollo" el vislumbre de la calidad de vida es un acicate para alimentar el valor de emigrar.

\section{La meta de la interculturalidad debe inspirar transversalmente todos los contenidos de la enseñanza}

Cada día parece más evidente, en el nivel conversacional, que los temas de los debates sociales más perentorios y de consecuencias más importantes y urgentes son aquellos que forman parte de los contenidos, los procedimientos, las actitudes y los valores que se relegan a objetivos "transversales", quedan marginados a la transversalidad. Los planes de enseñanza se construyen, respecto a ellos, en dirección divergente, con una fuerte tendencia a la sostenibilidad, el mantenimiento y la promoción del desarrollo científico técnico. Pero, al final, la sostenibilidad de los proyectos fundamentales a los que tiende una sociedad plural, o un continente en proceso de unificación, depende de planteamientos de transversalidad: educación de la participación política, cultura del consumo, cultura sanitaria, educación de la ciudadanía, educación de la convivencia intercultural, educación de la tolerancia social, cultura emocional, cultivo del pensamiento crítico, convergencia de Ciencia, Tecnología y Sociedad. Entre ese grupo de metas imprescindibles y transversales 
se incluye la referida "Educación Intercultural”. Creo que más importante que exista planificación de transversalidad es que los formadores sean testimonio de la misma. Esa transversalidad se nutre, precisamente, de los elementos fundamentales de las que Henri van Leer denominaba "las humanidades del siglo XX". Hoy, que tanto se habla de fracaso escolar, debiéramos atender, igualmente, a los comentarios de los profesores que aluden al fracaso de la transversalidad. Ya hay quien, ante la desorganización de las conductas juveniles de ocio y consumo, pide una nueva materia de educación para la salud: más transversalidad. El error puede llegar si alguno entiende que una formación en Educación para la Salud, es otra manera de hablar de medicina o de psicología, que la interpretan como formando parte de las ciencias de la salud. ¿Por qué no decir que estar bien educado es una manera de buscar estar sano? Además, todos creemos que es necesario mayor rendimiento en los aprendizajes de las materias "verticales". ¿Más tiempo de enseñanza, más enseñanzas, más formación del profesorado? En el día de hoy español, abrumados por la violencia doméstica y la agresividad de género, ya hay político que pide incorporar en la enseñanza de la ética unidades de cultura de género. La incorporación de estos contenidos de formación, que respecto a las trayectorias "verticales" de los campos de conocimiento parecen cortes transversales, creo que exigen un replanteamiento de los planes de enseñanza en vistas a la formación de la cohorte de edad de nivel obligatorio. No puede entenderse sólo como preparación a la vida activa ni como fuente para el mantenimiento del sistema de Ciencia y Tecnología; ante todo debe promover salubridad social, inspirar calidad de vida personal y sostenibilidad de la convivencia social.

El primer paso en la dirección de una formación intercultural es el de explicitar y ejercitar la comprensión del propio concepto de cultura.

\section{La cultura como término, como creación objetiva y como proceso intersubjetivo}

"Cultura" forma parte del grupo de los tres o cuatro términos de semántica más enrevesada de la lengua castellana. En muchas constituciones de Estados, el "acceso a la cultura" se afirma como una misión fundamental del Estado y un derecho fundamental del ciudadano. En cambio, en otros documentos oficiales, en medios de comunicación y en las conversaciones, el término cultura aparece asociado a los contextos más dispares, tanto positivos como negativos: "cultura del pelotazo", "cultura del ocio y tiempo libre", "cultura científica", "cultura de la droga". La asociación del término cultura, en expresiones como "cultura de..." funciona como una categorización del campo de actividad al que se encuentra asociado.

En un sentido directo, la palabra latina "cultura" designaba el "cultivo" (del campo, los árboles, los animales...) y, por extensión, el "cuidado" de algo. Parece que la primera vez en la que se hace uso metafórico de la palabra cultura, en un sentido formativo, es en las "Disputaciones Tusculanas" de Cicerón (106-43 a.C.), donde se afirma que "la filosofía es la cultura del alma"4, porque mediante ella el hombre alcanza el ideal de "humanidad", su condición propiamente humana. Durante la Edad Media "cultus" compone la metáfora que expresa la veneración y el homenaje que se dirige a la divinidad; en tanto que el sentido activo de la formación se expresa por la voz "perfeccionamiento".

La recuperación del sentido ciceroniano de la palabra y la conversión del proceso cultural en tema de estudio fue obra de Juan Luis Vives (1482-1540)5 ${ }^{5}$. Pero todavía se mantiene la palabra unida a un genitivo (cultivo de...), como reminiscencia de su origen bucólico. Francis Bacon empleaba la expresión "georgica animi" para 
indicar el procedimiento mediante el cual puede el hombre "cultivar" el sometimiento de la voluntad a las prescripciones morales y así conseguir la felicidad.

\section{La cultura como realidad objetiva}

Herodoto, sin emplear el término "cultura" fue, quizás, el primero en atribuir al fenómeno cultural una realidad observable y analizable. Para explicar el carácter hostil de las relaciones entre los griegos y los persas, busca los orígenes de tal situación y viaja a más de cincuenta comunidades culturales diferentes y registrando los relatos sobre sus orígenes, mostrando los caracteres diferenciales que presenta la religión, las manifestaciones artísticas y las prácticas de vida cotidiana ${ }^{6}$. En esta dirección se situó Samuel Baron von Pufendorf (1632-1694); advirtiendo el hecho de que el hombre únicamente consigue su verdadera condición dentro de la sociedad, empleó la voz "cultura" como el estado de cosas propio de la vida social. Entiende por cultura los descubrimientos y construcciones humanas, los quehaceres y el modo de vida, las instituciones de ayuda y asistencia dentro de la vida social, adquiriendo la voz "cultura" un significado objetivo: los bienes culturales. Esta acepción objetiva del término cultura se contrapone al significado del término naturaleza. Este término alude al mundo de los hechos físicos y biológicos, el mundo comportamental de los animales (naturaleza salvaje) y al estrato biológico y sus necesidades en los seres humanos.

La visión objetiva sistemática del concepto de cultura fue producto de la Ilustración francesa, por obra de autores como Voltaire (1694-1778), Montesquieu (1689-1755) o Turgot (1727-1781). En ellos se da una manifiesta diferenciación entre el sentido de la formación (cultura animae) y el sentido objetivo o de la producción y creación humanas -cultura objetiva-, para cuyo proceso y desarrollo en el tiempo se pretendieron encontrar, sin éxito, leyes peculiares ${ }^{7}$. Junto a ellos, hay que situar a Johann Gottfried Herder ${ }^{8}$ (1744-1803) por haber introducido alguno de los significados modernos de cultura: junto al sentido subjetivo (p.e. "cultura de la razón" o "cultura del lenguaje"), se añadía un sentido particular (p.e. "cultura de un pueblo") y un sentido general de "cultura de la humanidad".

Este espectro conceptual guió la elaboración de tratados de Historia de la Cultura y de Filosofía de la Cultura. En estos estudios se destacan tres categorías de cuestiones: (a) la creación de un aparato conceptual con el que dar cuenta de los diferentes aspectos a que hace referencia la noción de cultura ${ }^{9}$; (b) el análisis sistemático de la dinámica cultural, la "génesis", la "evolución", la "confrontación cultual”...; (c) y con tal aparato conceptual y la incorporación de metodologías específicas, construir el marco adecuado para el estudio de culturas particulares y para la crítica de los fenómenos culturales. Frecuentemente se alude a Tylor como hito en el planteamiento dominante, objetivo, sobre el concepto de cultura que domina en la Antropología como campo de conocimiento, y se toma su definición de cultura como referente para iniciar una reflexión sistemática. "La cultura o civilización, en sentido etnográfico amplio, es aquél todo complejo que incluye el conocimiento, las creencias, el arte, la moral, el derecho, las costumbres y cualesquiera otros hábitos y capacidades adquiridos por el hombre en cuanto miembro de la sociedad"10.

\section{La cultura como proceso intersubjetivo}

Desde el origen, pues, del término cultura, se dio una acepción como cultivo, como proceso intersubjetivo. Cultura como trabajo de la especie, de unos con otros, mediante el cual los productos culturales se 
transforman en bienes de uso, en instrumentos personales y sociales de acción ${ }^{11}$. El material con el que la mente opera, entonces, es material cultural. "Es la cultura la que aporta los instrumentos para organizar y entender nuestros mundos en formas comunicables"12. La adaptación fundamental de la especie humana ha sido la capacidad de objetivar la experiencia y preservarla en la cultura y la capacidad de convertir en proyecto y en proceso la incorporación de los bienes culturales a la actividad mental: lo que estrictamente denomina la Pedagogía formar la mente. La especie humana se encuentra tan adaptada a esta situación que, sin estar expuesto a esa formación de la mente en la cultura, o lo que es lo mismo, sin quedar inserto en el proceso intersubjetivo que hace significativo el contenido cultural, el ser humano es inconcebible, porque se trata de un proceso vitalmente necesario. Por eso también y con propiedad, muchos educadores identifican formación y socialización. La formación siempre tiene lugar en un médium cultural y recurriendo a recursos de la propia cultura. El fracaso educativo, no meramente el fracaso escolar, se produce porque fracasa el proceso intersubjetivo; no se trata de un error de concepto, o de una técnica equivocada, sino el desvío de un proceso, en cuyo origen pueden rastrearse muchas etiologías.

\section{La experiencia cultural en el contexto y en la situación de tránsito}

El mundo es ofrecido al sujeto en el contexto intersubjetivo no como un continuo, aunque sus receptores sensoriales estén permanentemente receptivos, abiertos y activos. Los acontecimientos, la acción, los instrumentos para la acción, la interacción, proporcionan bloques con sentido que la comunicación trata de hacer encajar y justificar en un todo, a veces lleno de ambigüedad, en ocasiones equívoco, en cualquier caso "familiar". Estos bloques de sentido han sido denominados esquemas, guiones, modelos culturales, memes. Estos modelos, el sujeto los incorpora y los emplea en la interpretación de su propia experiencia y como marco de referencia para estructurar su propia acción. La concordancia de modelos, no obstante los caracteres ideosincráticos que el sujeto aporte, es la medida de la comprensión social, la divergencia con ellos la fuente de negociación de la interpretación discrepante o de la acción disconforme, disidente o transgresora. En el acontecimiento o en la práctica es donde el guión se expresa objetivamente y en el contexto subjetivo de los actores es donde el esque$m a$ se actualiza en experiencia compartida o discrepante. El dentro y el fuera del sujeto son coordenadas esenciales en el análisis de la cultura.

Esa intersubjetividad tiene dos formas de expresión: la que se produce dentro de la trama social donde se vive y la que se produce dentro de la trama social a la que se accede cuando se produce una migración a otro grupo cultural. La intersubjetividad cultural tiene una forma de expresión dentro del propio nicho cultural y otra cuando se trata de relación entre sujetos de culturas diferentes. En el primer caso es experiencia de incorporación a la coincidencia cultural y el segundo es experiencia de divergencia cultural. Nos parece obvio que lo primero forme parte de la dinámica vital y lo denominemos formación; como también es habitual que al segundo le atribuyamos el carácter de un contraste para el que empleamos un término casi agresivo: confrontación cultural. Sin embargo, la comprensión profunda de la cultura advierte que donde fundamos nuestra identidad es esencialmente diversiforme y que, cada vez que rechazamos una diferencia, probablemente rechazamos una fuente de diversidad que compartimos en origen.

Desde la vertiente subjetiva en la interpretación de la cultura es desde donde construimos el concepto de identidad cultural, porque lo entendemos y lo vivenciamos como un modo unificado de vivir, de habitar, 
de pensar, de ser que nace con "nosotros". Precisamente la evolución del modo de vivir y de experientar el estilo de vida, junto al aislamiento geográfico, es lo que llevó a la divergencia entre culturas con orígenes compartidos. La movilidad en el espacio, la movilidad de los instrumentos y artificios en los que preservamos la experiencia (la de los humanos, la de los libros, la de los artefactos y la de los conocimientos, los intercambios lingüísticos o los de información) constituyó el más poderoso factor exógeno de la evolución de las culturas y lo que, hoy, nos plantea el problema de la interculturalidad. Por estos motivos, todas las culturas están en proceso de transformación y todas en proceso de transición.

En situación actual de contacto intercultural generalizado y de movimiento de transición acelerado, el fomento de la mentalidad pluralista se convierte en una meta de formación básica para la convivencia, lo que en términos europeos denominamos la Europa de los Ciudadanos. Porque las divergencias culturales que afectan cualitativamente a la convivencia no tienen origen únicamente en trasiegos de personas, también son generacionales, de afiliación ideológica, de rango de competencia y capacidad, de género y estatus. Para el cultivo de aquella mentalidad abierta a la pluralidad, de que hablábamos antes, proponemos organizadores de contenidos, marcos para el fomento de actitudes, criterios para construir estrategias, posiciones desde las que descubrir el valor del entendimiento social entre ciudadanos diferentes. La aplicación de los mismos tendría concreciones diferentes según los campos de implicación y según los tipos de responsabilidad de cada educador.

I. Valoración cultural de la movilidad en el espacio y el cambio de asentamiento.

II. Actitud crítica respecto al imaginario cultural.
III. Difusión cultural y desvelamiento del mestizaje a la conciencia.

IV. El diálogo y la conversación como el lugar de la cultura y por encima del territorio.

V. Abrir el contexto de referencia en vez de cerrarlo, la significación de lo local se encuentra en lo global.

\section{La valoración cultural de la movilidad en el espacio y el cambio de asentamiento}

\section{La importancia cultural de la movilidad en el espacio}

El primer tema de una educación intercultural creo que debe ser el de la importancia cultural de la movilidad en el espacio, frente a la sobrevaloración de la referencia territorial. Comprenderemos las características de la Sociedad Global si entendemos las consecuencias de la intensificación de las comunicaciones, de la movilidad integral en el espacio, ya sea movilidad de personas, movilidad de mercancías, movilidad de soportes de información o movilidad de información. No creo que se pueda entender en profundidad la Sociedad de la Información sin hacer previamente, al menos dos consideraciones: una acerca del papel de las comunicaciones y de los sistemas de comunicación, la otra acerca de las metáforas con las que se describe, su imaginario intelectual.

\section{La revolución de las comunicaciones}

Muchos son los autores que al identificar características y peculiaridades de las innovaciones más relevantes en la época contemporánea, subrayan de manera especial un proceso científico-tecnológico que denominan "revolución de las comunicaciones"13. 
El coeficiente de aceleración que connota la idea de re-(e)volución, hace referencia a un parámetro de fondo por el que los intercambios y las comunicaciones se sitúan en el núcleo de la dinámica de cambio en las culturas, desde la más remota antigüedad. Sobre estos ejes del intercambio-transporte de los medios y mediadores de comunicación entre grupos humanos con diferentes culturas han tenido lugar procesos de difusión de innovaciones técnicas, procesos asociados al multilingüismo y aquellos derivados del pluralismo cultural: cambios, afloramientos de nuevas formas culturales, extinciones de culturas. La contingencia de la implantación de la Sociedad de la Información llevará, de manera imparable, a una extinción masiva de culturas.

En la historia evolutiva de las culturas se integran, entre otros, los efectos de dos tipos de factores de movilidad: (i) Los efectos y consecuencias derivados del transporte, de las técnicas del desplazamiento en el espacio de personas y mercancías, del hecho mismo de que se desplacen de un núcleo social a otro personas y mercancías, porque unos y otras son vehículos de información, contenedores de material simbólico, de diseños de acción, de tema para la conversación y el pensamiento, de objetivos para la acción, de replanteamiento de aspiraciones; los mismos elementos que cambian de espacio, artefactos, cosas, productos o personas, con lo que hacen, lo que cuentan, lo que manifiestan pensar, lo que permiten hacer o construir..., constituyen elementos nuevos que se introducen en la ecología vital y mental de quienes ocupan el fin del trayecto de la caravana; elementos no previstos, elementos extraños que, al incorporarse, hacen "mestizo" y "criollo" el entorno referencial.

(ii) Los derivados de las comunicaciones en tanto que técnicas específicamente diseñadas para el transporte de la información, desde la propia lengua, los artificios lingüísticos, las técnicas de escritura, los códigos de señales, las vías públicas, el telégrafo, el teléfono, en tanto que vías de entrada comunicacionales; no sólo son activos en el proceso de mestizaje por lo que comunican, sino que también lo son por lo que inducen dentro de la comunidad de prácticas sociales. Baste para comprobar estos ejes de la dinámica cultural repensar los viajes de ida y vuelta de Colón, los efectos de los grandes movimientos de población. Estos medios, vías e instrumentos de información, hicieron posible en la antigüedad la existencia de comunidades multiculturales a las que se dieron nombre de Imperios. Los lugares culturalmente más florecientes y creativos se localizaron precisamente en zonas de encrucijada de movimientos de personas y mercancías, porque los generaron y promovieron, demandándolos o impulsándolos; de todo ello es una buena prueba el Mar Mediterráneo.

Este movimiento en el espacio, importante, vital y comunicacionalmente en todos los seres vivos, tiene una importancia fundamental entre los seres humanos. No somos una especie migratoria, pero somos una especie exploratoria que, frente a muchas categorías de problemas, entiende que "irse", "ir a buscarse la vida" constituye una solución. La cultura del espacio junto a la cultura social, probablemente, fueron las dos protoculturas de los humanos, por delante de la cultura de los artefactos. Coincido con quienes piensan que, tal vez, el hombre fue artesano por aplicar la inteligencia social a la resolución de problemas técnicos.

De la importancia de la movilidad en el espacio dan cuenta tantos libros cardinales en todas las culturas que contienen en su interior un viaje: desde la Iliada a Don Quijote, pasando por el camino y el recorrido que unifica lo esencial, tanto en el antiguo como en el nuevo testamento, de la Biblia y los Evangelios. La respuesta a la significación del caminar en el fundador es el peregrinaje del creyente a lugares significativos. 
Repetimos que no entendemos estos organizadores como tópicos para una disciplina, sino como organizadores transversales de significación que pueden aplicarse con criterio transversal en las materias más diferentes, desde la literatura a las ciencias sociales y naturales. Únicamente desde estas coincidencias de perspectiva el alumno experimenta el valor experiencial de la transversalidad. Lo que sí pueden es constituir núcleos para la sensibilización del profesorado en la cuestión.

\section{Actitud crítica respecto al imaginario cultural}

\section{El imaginario y las metáforas como el adobe de la identidad cultural}

$E l$ segundo elemento que proponemos como organizador de la educación intercultural pretende acrecentar el pensamiento crítico, por la vía de identificar y diferenciar entre realidad e imaginario cultural, por la vía de identificar el imaginario cultural y valorarlo críticamente.

La construcción de metáforas, "pensar imaginando", promueve estados mentales que preceden a la elaboración conceptual, que sirven de fondo para la actividad mental, que funcionan como híbridos de tránsito, antes de formularse en hipótesis o concretarse en teorías (Preta, 1993, p. 11). Estos imaginarios juegan un papel decisivo en la actividad mental y en el intercambio social. Ese espacio interior adquiere, en el trato que con él establece el sujeto, características muy semejantes al espacio del mundo de la vida; a veces se confunde con él, sin saber ya si estamos en el real o en imaginario; a veces, incita a actuar en el real como si estuviéramos en el imaginario. Un ejemplo de esto es, a veces, la actividad poética (Ross, 1992, p. 9).

Se suelen tomar como referente claro del imaginario cultural los "mitos" sobre el origen del mundo, de la vida, del grupo de referencia y del primer asentamiento territorial; los cuentos y leyendas, donde se deposita buena parte del código moral y de los valores primigenios de la sociedad. Se emplea el pasado nostálgico para construir una "casa mental" en la que creemos vivir, de la que creemos proceder, de la que no queremos salir y ...en la que nos resistimos a dejar entrar a extraños. Lo expresamos al ponderar el "soy de..." o "soy un...". En la educación intercultural es imprescindible identificar y valorar este imaginario cultural, no para prescindir de él, porque proporciona seguridad, sino para no quedar alucinados en él y crecer a partir de él; mostrar que los demás proceden de similar manera; y plantear el problema radical de que esas "casas mentales", donde se guarda y asegura la diferencia, han de hacerse compatibles con la otra habitación donde moran los ideales de pertenencia a la humanidad. Cuando confrontamos con sentido crítico uno y otro espacio mental, como cuando nuestra identidad y la extraña como materia para la deliberación, dentro del marco de unidad en lo humano, pasan cosas; pero, son cosas que tienen que pasar. De la instalación en la percatación de la diferencia se pasa a la movilización de la actitud de deferencia. Seguiremos valorando el propio imaginario cultural, pero su valor no lo estimaremos en diferente moneda; aceptamos valorar desde la misma unidad de valor que el extraño. De ahí que el convivir, tenga que ser, necesariamente, una decisión compartida. La hospitalidad queda así definida por la doble aceptación, en el territorio y en la casa mental del imaginario cultural de todos aquellos que compartan con nosotros el espacio convivencial.

La epistemología ingenua piensa que nos acercamos al mundo con el ojo limpio y que el conocimiento es producto de una observación desnuda. Nadie como Emmanuel Kant ha afirmado con tanta contundencia el planteamiento inverso de que las verdades acerca del mundo son 
construidas en las cabezas de los seres humanos, fabricamos mundos, no nos los encontramos. Por la simple descripción de la experiencia, parece seguro que disponemos en nuestra mente de un sistema de procesos que da cuenta de las regularidades, y un segundo sistema de procesos de activación ante lo inusual, lo impredecible, lo "nuevo". Por el primero, nuestra mente trata de mantener la percepción del entorno dentro de marcos de referencia estables; por el segundo, ponemos en marcha energía mental de indagación para explicar lo impredecible o actuar ante lo sorprendente (Preta, 1993, p. 129 ss.). De ahí que tratemos con epistemología diferente los acontecimientos "dentro" de la familiaridad cultural y los que tienen lugar como pertenecientes al espacio "extraño".

Con el imaginario cultural los sujetos y los grupos elaboran identidad cultural, que no es sino la conversión en cosa real ("hipóstasis") de lo que no es, en definitiva, más que una seguridad y conformidad con los propios materiales (esquemas, modelos,...) de su cultura; los componentes de la casa mental son vividos y defendidos en persona. Este aspecto de la representación lo denomina Moscovici “objetivación”. Este es el gran trabajo que lleva a cabo la imaginación sobre la materia de la cultura: en el imaginario la cultura se transforma en identidad. El paso siguiente es apreciar la materia cultural o los rasgos de la apariencia del diferente como "material extraño"; incorpora a este proceso un diferencial emocional de amenaza. La no familiaridad deja inerme y sin claves para comprender. La valoración de lo no familiar propende a la alerta y al rechazo. Nuestra mente emplea la emoción como atajo para la razón, cambia seguridad por precisión. Lo mismo da que se trate de "mala catadura", humano de otro "color", costumbre alimentaria o indumentaria. Es decir, el imaginario proporciona materiales para construir el autoconcepto personal y social y para decidir la manera de preservarlo y, si es el caso, defenderlo.
De ahí que la reflexión crítica sobre ese imaginario es fundamental para la valoración de posturas interculturales razonables. $\mathrm{O}$, lo que es lo mismo, el acercamiento crítico al imaginario cultural es un elemento esencial de la formación intercultural, de la formación de un pensamiento pluralista. La forma más sencilla de fomentar este pensamiento crítico es "mostrar lo que es propio de otros", ver otros puntos de vista y tratar de convivir con ellos. La consecuencia inmediata es la de "relativizar" el valor del propio imaginario sin renunciar a él, un cambio de moneda. La consideración de lo extraño modifica necesariamente la unidad de valor con la que se mide el propio imaginario cultural. Por eso, el factor fundamental de incorporación cultural es el aprendizaje de la lengua nativa, el instrumento primordial de preservación de la experiencia cultural entre los humanos. Pero, por eso mismo, los dos factores básicos de educación intercultural son el aprendizaje de idiomas "extranjeros" y el "viaje cultural" (viajar para aprender); hablar de otra manera arrastra a hablar de otras cosas y salir invita a revestirse de otras identidades. Algún día, tendremos perspectiva para valorar lo que ha hecho por la convivencia intercultural de los ciudadanos europeos el conjunto de programas que están fomentando la movilidad de estudiantes y profesores por Europa y por el mundo.

\section{La identidad y la identidad cultural como hilo en un relato experiencial}

En el imaginario cultural, la identidad se alimenta de "memoria". Existe la identidad cultural en la medida en que se hace real con recuerdos, tradiciones, hábitos, modos de hablar. Las representaciones sociales que constituyen lo que los grupos denominan identidades serían imposibles sin esa "memoria"; enseñar identidad es "contar relatos-retazos del imaginario cultural". 
Si no sonara irreverente diríamos que la identidad cultural se alimenta en el "contar cuentos", recontar el pasado que se conserva en la casa mental del imaginario cultural. De esta manera, la identidad demanda "fidelidad", conservar la identidad cultural consiste en un cierto modo de recordar; y este mantener vivo el recuerdo alimenta la identidad (“in memoria"). Vivimos los estados de cosas presentes y sus formas de expresión "en tiempo real", como resultado circunstancial, pero son convividos y marcados ("huella"), interpretados, desde la memoria cultural. Huella, tanto en la memoria individual como en los elementos objetivos de la realidad, normas, organizaciones, esquemas de comportamiento dominantes (memoria colectiva). Esta memoria ha sido alimentada en el trato social, a través de los significados con los que opera el lenguaje, en los diseños significativos que contiene el espacio, al vislumbrar las formas y los contenidos de las representaciones sociales de los demás. "Una parte significativa de las memorias de la experiencia personal es el resultado de conversaciones" (Rosa-Bellelli-Bakhurst, 2000, p. 49). Por lo tanto un grupo entiende que es, lo es, porque eso es lo que comparte en la acción comunicativa, en el tema y en el diferencial emocional asociado al tema; los demás elementos de la memoria histórica, carácter territorial, lengua dominante, tipología organizacional y cristalizaciones culturales, constituyen los "argumentos" del tema y el alimento del diferencial emocional. El sostenimiento de la identidad se encuentra sometido al mantenimiento del tema, al mantenimiento de la coordinación de los argumentos del tema. Por eso las culturas funcionan como sistemas clausurados de conversaciones; la educación funciona como sistema para la reproducción de la clausura del tema y como mecanismo preservador-reproductor del "meme" o esquema cultural (S. Blackmore, 2000).

\section{Componentes de la representación}

Según cuanto venimos planteando la representación de la identidad cultural o social de un individuo o grupo incorpora: (i) Imágenes (imaginario), el objeto de las representaciones se configura como si fuesen un icono (p.e. entrar en Europa, habla de morada); (ii) sistemas de referencia u organizaciones de contenidos cognitivos que actúan como fuentes de recursos para la interpretación de los acontecimientos que se presentan (p. e. la identidad cultural está en peligro si aumentan los que vienen "de fuera"); (iii) marcos decodificadores e interpretativos del contenido de las comunicaciones (p. e., todos los observatorios sociales muestran que en la Comunidad Autónoma Vasca el nivel de vida es el mas alto del territorio español, sin embargo, el núcleo más duro del nacionalismo justifica su acción radical por lo mal que están las cosas); con los mismos datos, si no es por el efecto de marcos decodificadores diferentes, no es posible obtener conclusiones tan extremas. Por el segundo y tercer componente tiene lugar lo que Moscovici califica de "anclaje". El anclaje, tiene una clara analogía con el fenómeno denominado en pedagogía aprendizaje significativo; los elementos con que se elabora la representación se incorporan significativamente a la estructura cognitiva del sujeto. Precisamente por ello el individuo es capaz, mediante la representación objetivada, de elaborar interpretaciones coherentes con ellas de nuevos datos o situaciones y orientar los comportamientos y las relaciones sociales. En el anclaje es donde encuentra la representación su consistencia cognitiva y su inercia al cambio. Consecuentes con este planteamiento, Jodelet (1986, p. 474) define así la representación social: "Las representaciones sociales constituyen modalidades de pensamiento práctico orientados hacia la comunicación, la comprensión y el dominio del entorno social, material e ideal... La caracterización de los contenidos o de los procesos de representación ha de referirse 
a las condiciones y a los contextos en los que surgen las representaciones, a las comunicaciones mediante las que circulan y a las funciones a las que sirven dentro de la interacción con el mundo y los demás".

Así dicho, todo parece ordenado en la representación social, pero más bien se trata de una organización caótica entre registros del pasado y un "mare mágnum de símbolos, imágenes, explicaciones y relatos sobre lo acontecido en el pasado, sobre la justificación del presente y sobre el futuro que desear, temer, luchar para conseguir, etc." (Rosa, A.-Bellelli, G.-Bakhurst, D., 2000) p. 71.). Deja de ser un galimatías en los discursos oficiales, pero no en el mosaico de identidades que se asocian e identifican con la identidad colectiva.

La sugerencia fundamental en este organizador, al igual que en el anterior proponíamos el estudio de otras lenguas o el conocimiento atento de otros lugares de cultura, consiste en conocer y estudiar otras memorias, analizar dependencias, retroceder en el tiempo, ampliar las referencias, degustar otros imaginarios e identificar su sentido y su valor. También es de recomendar el análisis del propio lugar cultural con interés "clínico", con el afilado bisturí del anatómico, identificando la diferente ontología de los materiales. Al hacerlo, evidentemente, hay partes de la adhesión que se debilitan en beneficio del fortalecimiento de otras identidades allende la propia frontera.

\section{Difusión cultural y desvelamiento del mestizaje a la conciencia}

\section{El mestizaje como concepto y como perspectiva}

Muchos sujetos, por lo tanto, construyen, objetivan y anclan la imagen identitaria de una forma tan rotunda y aparente como su propio rostro, con la diferencia de que se trata de un rostro compartido.
Como término aparece mestizaje en el contexto de la colonización, con una procedencia latina que alude a mezcla ${ }^{14}$. Pero, sobre todo, el término hace referencia al resultado de fenotipos y apariencias físicas y de color de piel (Bonniol, J.L., 1992), las cuales se toman como marcas para la estigmatización y la exclusión de la que eran objeto privilegiado los diferentes en origen. No sólo abarca el término las apariencias corporales ("mezcla de sangre"), también las prácticas comunicacionales ("lenguas criollas") y las prácticas religiosas ("religiones criollas"). En este contexto se plantea, igualmente el término "cruzamiento de culturas". En opinión de F. Laplantine (1997, p. 8) "El mestizaje (coloquialmente) mejor comprendido implicaría la existencia de dos individuos originalmente "puros" 0 , más generalmente, un estado inicial -racial, social, cultural, lingüístico-, un conjunto homogéneo que, en un cierto momento, encuentra otro conjunto dando lugar al nacimiento de un fenómeno "impuro" o "heterogéneo". Pero ésta es la forma superficial de entender el concepto, aun cuando haya sido construido para identificar, primariamente, la "ejemplaridad" o la "repulsión" de "mezclar su sangre", fuera de la homogeneidad que se la proporcionó.

No es difícil rastrear en el vocabulario y en la experiencia de los grupos humanos indicios por los que se mitifican y elevan a la condición de fantasma determinados rasgos corporales. El cuerpo no es vivido sólo dentro de una experiencia fisiológica, ni como esquema dinámico-anatómico ("esquema corporal"), sino como cuerpo simbólico. Dentro del simbolismo es apreciada, ante todo, la diferencia de apariencia corporal, de manera especial la de los rasgos y el color de la piel, las malformaciones orgánicas, determinadas enfermedades y sus secuelas evidentes; con tal convencimiento de que la apariencia corporal constituye indicio de modos de ser, que llegaron a plantearse patrones corporales de los que inferir rasgos de personalidad e incluso patologías 
comportamentales y malignidad moral. Aunque el cuerpo pueda mostrar indicios, en algunos casos, de disfuncionalidades que se proyectan en el comportamiento, la mistificación de los indicios se presta a transformarse en argumento para toda clase de estigmatizaciones sociales o atribuciones de riesgo para la moralidad pública, que no otra cosa son muchas formas de exclusión y de repulsión de la diferencia.

\section{Utilidad del concepto mestizaje}

Si al concepto lo libramos de excrecencias históricas y fetichismos ofrece una pertinencia para el debate político y cultural actual, precisamente porque plantea una vía alternativa entre la disolución de identidades sociales -expulsiones, aniquilamientos raciales, racismos, atrincheramientos nacionalistas, disoluciones integradoras...- $\mathrm{y}$ formas de privilegio de origen, pureza de lengua, de territorio, o de memoria histórica. El mestizaje como concepto constituye la cara oculta del privilegio biológico de la especie humana, mediante el cual posee la capacidad de resolución de conflictos y confrontaciones empleando el diálogo. Contra esta peculiaridad van todas las formas de reducción a la unidad y toda forma de ablación simbólica de las diferencias. Hoy, parece necesario incorporar el concepto de mestizaje cultural para aliviar la tensión social cuando se reivindica con una cierta intensidad el nacionalismo.

Todos debemos asumir que todas las culturas son mestizas (Magris, CL., 1992), que todas las lenguas son mestizas por más que se estipulen "fronteras interiores", como las del buen uso y la gramática para la lengua, y fronteras exteriores como la adjudicación de territorio. Dentro de estas fronterizaciones aparece siempre el mestizaje, como consecuencia de la movilidad de la gente, del transporte de todo tipo de "artefactos culturales" (desde una receta de cocina a la red de fibra óptica); aparece el fenómeno cultural "criollo"; aparecen evidencias de que el mestizaje y el criollo es el estado natural de las culturas; si se quiere, también se puede expresar como que la confrontación intercultural es una dinámica cultural permanente, que pone a prueba los valores del "bon homme" que describe Montaigne en sus Ensayos y los valores de las buenas sociedades o Sociedades Abiertas, las cuales no son otras que las sociedades plurales: conscientes de su pluralidad y pluralistas de mentalidad. Cuando se pierde de vista esto, en el plano personal y en el social, y las pasiones se inflaman o rebosa la emocionalidad en los recipientes de las identidades, cuando por no saberse plural se vivencian identidades amenazadas, la persona y los grupos tienden más a cerrarse que abrirse.

\section{El tiempo de la identidad y de la limpieza de sangre}

La historia, en el contexto de las identidades, adquiere la función, en determinados grupos, de justificar reivindicaciones de "monopertenencia identitaria". Pero, ¿a partir de cuándo se empieza a contar el nacimiento de una identidad cultural? Si tomamos como referencia de territorio la zona del mediterráneo, los árabes los denominaban "al-bahr al-mutawassit" (superficie de agua que se encuentra en el centro), porque entendían que era el centro geográfico del mundo. Los romanos, en cambio, a fuerza de recorrerlo, lo denominaban "Mare-magnun". Maremagnun es la mejor metáfora para señalar una identidad hecha de milenarias migraciones, alquimia cultural de unos pueblos a partir de otros, deportaciones, persecuciones y cruzadas.

La idea de mestizaje se contrapone a la de "limpieza de sangre", que inspiró Tribunales de Inquisición, expulsiones masivas (judíos), masacres (guerra de Yugoslavia), destrucción de patrimonios culturales 
(Talibanes). La "limpieza de sangre" se construye sobre una pérdida de memoria, represión mnésica, que olvida el pasado mestizo de toda cultura. Muchos componentes de identidad cultural, se hacen tan connaturales de la comunidad que los disfruta que terminan por perder toda su referencia original y su raíz heterocultural. La historia de cualquier cultura, o la de cualquier comunidad, salvo que se limpie sectariamente, es la historia de un mestizaje permanente en todos los órdenes y niveles del edificio cultural (patrones alimentarios, patrones indumentarios, creencias religiosas, terminologías...).

Independientemente de la idea original, el mestizaje ha de entenderse en sentido cultural. Sorprende que la desvalorización del mestizaje cultural sea compatible y defendido por comunidades que poseen "culturas compuestas" (Glissant, E., 1954), como la europea en toda su amplitud o tomada por zócalos regionales, mientras que zonas territoriales "conquistadas", en cuyo pasado todavía está vivo un etnocidio, fomenten como valor social la defensa de la "democracia racial", la exaltación del valor criollo. Lo que habitualmente denominamos "raíz" cultural es siempre "rizoma", urdimbre de receptores culturales que se apropian de acervos obtenidos en muy diferentes zócalos. Contra toda miopía cultural y obcecación en un imaginario identitario, la pluralidad cultural no constituye una situación provisional, sino el valor constituyente de toda cultura.

El mestizaje es como la varilla en el reloj de sol, la que proyecta la sombra, marca la dirección y perspectiva desde la que se valora vitalmente la cultura: el estado cultural del que se viene o el estado cultural al que se va. "El mestizaje es un hecho que no tiene nada de circunstancial, de contingente, de accidental" (Laplantine A., 1997).

\section{Pluralismo y solidaridad}

Desde el momento en que se acentúa como carácter de la sociedad el movimiento en el espacio y el cambio de asentamiento, se impone a las agencias de formación un tiempo cultural en el que las horas se marcan con "pluralismo" "multiculturalidad", "multivaloración", "multiidentificación", "mestizaje", "criollité" (en español la condición criolla no ha superado el estado sustantivo para transformarse en cualidad). No vamos a hacer el ejercicio académico, aquí, de detenernos en distinciones. Cualquier forma de interpretación de la multiculturalidad y del multiculturalismo se fundamenta en el hecho de una cohabitación posible y de la coexistencia de grupos culturales diferentes. La forma violenta de confrontación entre culturas se alimenta de afán de protección o de afán de absorción desde un pasado identitario: dos formas de violencia simbólica que, pueden cambiar a otro registro de violencia, caracterizada por su antimestizaje. El presente y el futuro identitario real está formado por una dinámica de mestizaje constante.

La auténtica implantación de los valores de solidaridad-libertad-tolerancia tienen lugar cuando, además de "tolerar"respetar los valores ajenos, se afirma el pluralismo como propio, cuando se asume en el marco socio-cultural el valor de la diversidad y el disenso que se defienden como necesarios en la vida pública, "entre los nuestros"; pero tiene que ser posible la concordia desde el disenso; este es el sentido del sistema de partidos políticos. En la antítesis se encuentra el implícito conversacional, de muchos debates, por el que la diversidad es la fuente de la discordia y la ruina de las identidades sociales.

El ciudadano afronta, al menos, siguiendo a Sartori (2001) en este punto, tres grandes niveles de heterogeneidad social:

(a) El nivel cultural $^{15}$. En este nivel el objetivo de formación es el del "reconocimiento recíproco", en su antípoda estaría el concepto de sociedad multigrupo con la estipulación de secesión y fragmentación cultural. 
(b) El nivel social. Aquí el objetivo es el del compromiso en la acción social mediante asociación voluntaria y donde el sujeto puede implicarse en asociaciones múltiples.

(c) Y el nivel político. El objetivo es la concordancia en las vías de resolución de conflictos, cultura de paz, y posibilidad de disenso en cuanto a los programas de actividad pública.

Tanto los movimientos autonomistas y los nacionalistas, más radicales aunque menos plurales, muestran cierta insuficiencia del Estado Nación como principio único de organización social. Pero, esta situación revitaliza la necesidad de identificación con ideas de "comunidad" pluralista. En las acciones de formación, el compromiso con los tres niveles no es igualmente vinculante. El espacio de la formación debe profundizar en el valor del reconocimiento recíproco como meta formativa en comunidades formadas "por todos los de aquí y los que vienen", ya que se trata de construir tolerancia y solidaridad con el diferente y el extraño. En el nivel social debe fomentar la formación, igualmente, la aceptación del disenso al solidarizarse con la posibilidad de asociacionismo múltiple. Con este fundamento puede tomarse partido político con las actitudes y los procedimientos pacíficos, porque el principio de concordia es la búsqueda de política de paz.

Estos temas, que forman parte de la transversalidad de la formación en documentos oficiales, pero no parecen tener sitio claro ni adecuado en la "Zona institucional de construcción del conocimiento", ni parece siquiera que sea, salvo en momentos cruciales como en el debate la Ley de Extranjería española o el debate nacionalista, un tema preocupante en los órganos máximos de representación. Cuando las coaliciones políticas se blindan se rebaja el debate sobre "la sociedad abierta y sus enemigos". El debate se traslada a los medios de comunicación social y, muchas veces, hay que quedar a la espera de acontecimientos traumáticos. Este debate antes que debate político es tema de reflexión ética y de reflexión humanista.

Una sugerencia de formación en la interculturalidad desde este organizador, es la de recomponer las narrativas históricas. Una forma puede ser confrontar las versiones sobre un mismo acontecimiento dependiendo del lugar del narrador en el conflicto, para reconstruir la memoria y con ella las representaciones sociales. Esta es la tarea que tiene ante sí, p.e., la reconstrucción representacional de Europa y el esfuerzo que vienen realizando algunas confesiones religiosas bajo lo que se denomina actitud ecuménica.

\section{El diálogo y la conversación es el lugar de la cultura, no el territorio}

\section{La cultura como sistema de conversación}

Para muchos, la prioridad representacional no se centra en la condición mestiza sino en una nostálgica identidad. Para ello, realizan con su imaginario un esfuerzo que favorezca la pervivencia del pasado identificador, es lo que se llama afirmación étnica o protección de la identidad cultural; en este sentido se comprenden muchas iniciativas de políticas culturales que fomentan la recuperación de tradiciones o el mantenimiento de prácticas ancestrales: lingüísticas, alimenticias, indumentarias, de motricidad expresiva o de expresividad plástica. El problema empieza cuando de la reivindicación étnica se pasa a la reivindicación territorial. Es la misma diferencia que media entre la afirmación "nosotros somos diferentes" y la que estipula que "este territorio es nuestro”. La reivindicación territorial es compatible con el respeto a la pluralidad, pero aquella se plantea como exigencia previa. Este es el riesgo básico 
de los nacionalismos y la antítesis de la mentalidad pluralista. El "locus" de la identidad cultural no es el territorio sino la conversación; el lugar de mostración de la identidad cultural es el intercambio conversacional en convivencia territorial. Este es un nuevo componente referencial de una educación intercultural.

\section{Identificación antropológica del espacio conversacional}

Las cosas son "mundo" porque hay hombres que tratan de vivir en él entendiéndolo, buscando en él su sitio y creando un mundo personal (García Carrasco, J. García del Dujo, A., 2001). Tanto el entendimiento como la búsqueda de sitio están asociados a la actividad intersubjetiva de coordinar acciones de comunicación: conversaciones. Mediante las palabras, y las demás categorías de actos de habla (Austin, J. L., 1971) que intervienen en las conversaciones, los hombres se intercambian contenidos mentales con los que trazan senderos en el mundo y hacen transitable la realidad. De esta manera se asocian la experiencia del suceso, la conciencia y la capacidad comunicativa de la experiencia a través del lenguaje. Esta habilidad narrativa es una disposición de la mente para "reconstruir" el Yo, el nosotros y todo lo demás; se elabora para sí y para los demás. En buena medida, en el propósito educativo de incentivar contenidos y promover actitudes respecto al mundo, respecto a sí mismo y a los demás, está inserto el desarrollo de esa "sensibilidad narrativa" (Bruner, J., 1999, p. 60) primaria, que incorpora los artificios narrativos de las conversaciones y las habilidades conversacionales.

El objeto privilegiado de la narración, es la propia vida. El carácter representativo de la narración respecto al sujeto, lleva a Bruner a proponer que "texto, en este sentido, equivale a un informe narrativo conceptualmente formulado de lo que ha sido una vida" (Bruner, J.-Weiser, S., 1998) o de lo que ha sido un acontecimiento. El que unos sucesos se inserten y otros se descarten es un elemento de la significación de la versión narrada, el pasado se constituye en esa versión. Bruner propone que precisamente esta narración-invención del YO sido/siendo es un mecanismo de formación de la mente; en él iniciamos la definición del mundo, el alcance de nuestra acción y se elabora la índole del pensamiento. Esta teoría sobre uno mismo funciona como una de las "herramientas" que Vygotsky reclamaba como mediadoras de las funciones mentales superiores (Bruner, J.-Weiser, S., 1998). Se trata de un "texto" no por el hecho de ser narrada, sino por el hecho de que la actividad de recuerdo implica una esquematización por la que se otorga coherencia a los episodios; en esa esquematización intervienen reglas de uso lingüístico y reglas de construcción narrativa. No se trata de una reproducción sino de una memorización motivada. En la concepción de esta narración biográfica, cada suceso no se inserta únicamente por la información que produjo, sino que su significado se construye también dentro del marco emocional desde el que el sujeto participó en el acontecimiento y desde los esquemas interpretativos socialmente asumidos... No debe confundirse esta narración "in mente", con el mero mostrarla en expresiones. La narración se construye aunque se tengan dificultades para expresarla, la narración es esencialmente el contenido de lo narrado, la experiencia vivenciada que se encarna en palabras. Nuestro pensamiento siempre se encuentra configurado lingüísticamente (Arent, H., 1996). No tener facilidad de palabra o ser introvertido no es lo mismo que parálisis narrativa, el "intérprete" interior de la experiencia parece una estructura funcional mental conectada-disociable del sistema funcional del habla (p.e., en los mudos) (Gazzaniga, M., 1999).

Por la fuerza de construcción de identidad que posee aquella narración es 
por lo que los nacionalismos, ortodoxias y fundamentalismos procuran que la escuela se convierta en el espacio para la construcción de la narración de etnicidad, con prioridad a cualquier otro tipo de historia o narración.

Fundamentando esta habilidad narrativa se encuentra lo que se denomina "teoría de la mente", la capacidad de construir creencias acerca de la mente (intenciones, opiniones...) del otro, la predisposición a aceptar y beneficiarse de la experiencia narrada de la persona en quien se confíao-se-depende. En virtud de ello, el recurso formativo primario de nuestra especie consiste en "situarse en la mente del otro".

Esta narración interpretadora, que se manifiesta en la conversación, constituye la forma primaria del pensamiento. Los contenidos de esa narración se organizan dentro de tramas de intersubjetividad. El sujeto vive mentalmente en ellos. En mucha parte constituyen convenciones sociales y representan el rasgo primario de la cultura, el que arropa y da razón de otros rasgos técnicos, institucionales, o de artefactos literarios (Olson, D.R., 1998) como los mitos, cuentos y leyendas. El ejercicio de esta habilidad narrativa es la que proporciona la forma comunicable y negociable al pensamiento.

\section{El carácter conversacional de toda cultura}

Tanto Habermas como Maturana situan el "consenso", o la "consensualidad" como el pro-o-contra de la coordinación de las acciones implicadas en la interacción (unas acciones favorecen el consenso otras lo impiden o destruyen). Es en esta acción, conversación, en la que se "produce el entrelazamiento de lo emocional y lo racional" (Maturana, H., 1995. P. 19), donde más se ejercita la habilidad más característica de la especie: la "habilidad de resolver nuestras diferencias emocionales y racionales conversando". El concepto de participación social tiene, además, la dimensión de la implicación en los proyectos institucionales, la colaboración en el trabajo colectivo; pero, en lo uno y lo otro se da una dimensión de participación en la dinámica comunicacional colectiva, en la construcción y solución de nuestros proyectos y problemas a través del diálogo social. Para comprender esta propuesta de análisis es preciso trascender el carácter episódico e incidental de la "conversación", en su sentido coloquial, para situarla en el nivel de una categoría general. Desde ella, entonces, el debate social, el sistema de los medios de comunicación, las instituciones de formación,..., la "lección" , constituyen formas complejas de conversación, formas reconstruidas por la integración de otros soportes comunicacionales. En esta apreciación se funda la demanda generalizada de "hablar" para la calidad de un entorno convivencial.

Maturana subraya que lo importante en la conversación no es el lenguaje como tal, sino el "lenguajear", el conversar en el que adquiere su sentido el lenguaje; es el "instrumento" más característico que emplean los humanos para llevar a cabo con éxito su particular modo de vida. En este ámbito de la conversación se encuentran concatenados y embutidos los procedimientos característicos del razonar, la propuesta de argumentos, y la estimación de dominios de acción mediante diferenciales emocionales ${ }^{16}$.

De la misma manera que el consenso es el mecanismo social mediante el cual se asume el sistema simbólico de la colectividad, la congruencia emocional con los otros con los que se convive es lo que constituye la configuración emocional del individuo, el diferencial emocional de las conversaciones. La muestra de lo uno y lo otro es el contenido objetivo básico de la cultura. El trasiego cultural básico y en el que participan-no-participarán todos tiene lugar en lugares públicos: en la calle, en las instituciones..., o en lugares comunes como la morada... El valor que el sujeto da 
a su vida o entiende que recibe de la vida lo manifiesta en estos lugares de conversación. Este poder de mostración y esta cristalización de la identidad es el que intenta aprovechar toda la clínica y la terapéutica asociada a la conversación (Shazer, S., 1999)17, desde el Psicoanálisis a la Terapia familiar. También es el motivo por el que se entiende una competencia pedagógica en el trabajo de la formación las denominadas "habilidades conversacionales".

Una cultura, afirma Humberto Maturana (1995), es una red de conversaciones. El proceso vital real y común tiene lugar en la experiencia de la coordinación de acciones y en la experiencia de la red de conversaciones que la define. Tanto en sentido positivo donde el llevarse bien es aproximación al entenderse hablando, como en el negativo de no poder actuar al unísono porque las conversaciones permanentemente se abortan.

Un testimonio impresionante de esta dialéctica lo hemos vivido en la interpretación de la Marcha Zapatista que terminó el 11 de marzo (2001) en la Plaza del Zócalo mexicana. Se subrayaba su perspectiva interculturalista $^{18}$, la imposibilidad de conseguir la convivencia ciudadana desde organizaciones político-militares, que la formulación de las fragmentaciones sociales desde el punto de vista de confrontación entre hegemonías aboca a los frentes de liberación nacional, la transformación de las armas en palabras ${ }^{19}$. Que las armas dejen sitio a las palabras no hace la tarea del entendimiento social más liviano.

\section{Las culturas como sistemas conversacionales clausurados}

La culturas, concluye H. Maturana, son sistemas clausurados de conversaciones, organizaciones conversacionales; precisamente por esta propiedad de la clausura es por lo que su proceso en el tiempo depende, mientras permanezca su aislamiento, de propiedades internas. Su permanencia será dependiente de sus modos de transmisión y de los mediadores empleados para preservar y transmitir los contenidos culturales que cristalizan, en buena medida, como temas de conversaciones. La identidad de una cultura se muestra tanto en sus productos (técnicas, organizaciones,...) y hechos culturales, como por sus modos de transmisión; la transmisión cultural es un mecanismo de conservación y dinámica cultural. Dado que a la base de la cultura se encuentra la interacción, la cultura se encuentra en estado permanentemente abierto a incrementos en complejidad. Un modo de vida en tanto que acontecimiento cultural, es tanto modo de vivir en el mundo como de opinar sobre él; entonces, el modo de vida es al mismo tiempo punto de vista. La calidad convivencial de la identidad cultural, la posibilidad de entendimiento social dentro de la interculturalidad se encuentran condicionadas por los propios procesos de transmisión cultural.

Es el espacio comunicacional el elemento diferenciador de las culturas, de la misma manera que el espacio ecológico es el contexto de la especiación en el mundo de los seres vivos. Lo que nos lleva a la advertencia de que los sujetos entran en comunicación a lo largo de un tiempo dado dentro de espacios seriados; en la interacción cambian los contextos, además de los interlocutores.

De estos planteamientos teóricos se infieren multitud de reglas y estrategias. Obtener esas consecuencias para la práctica puede constituir un buen ejercicio de comprensión de las dificultades y estrategias de la interculturalidad. Pongamos algunos ejemplos:

Para orientarse en un entorno nuevo siempre se requiere la comunicación; la desorientación de la actividad en un contexto dado siempre puede expresarse en términos de mala comunicación; la comunicación siempre será una vía para la mejora de la calidad de la orientación de la acción. 
La aplicación de estos principios a un contexto de aula es palmaria. Aumentar la comunicación es la fuente de reducción de todo tipo de problemas resultantes de la inmigración de unos en los contextos comunicacionales de otros.

- En correspondencia, la incomunicación es el mecanismo más potente de fijación de la orientación; el aislamiento comunicacional es el mecanismo por el que la dinámica cultural lleva a la maximización de las diferencias y al enquistamiento de la distancia comunicacional entre los que están y los que llegan.

- El aislamiento al que generalmente se somete la conducta disfuncional en cualquier sistema de comunicación, el aislamiento y la segregación, por sí mismos, nunca puede llevar a la reorientación. Este principio afecta a todas las formas de inserción: inmigrantes, marginados, individuos con déficits, delincuentes, drogadictos... (García Carrasco, J.-García del Dujo, A., 2001, cap. 10).

Una sugerencia de interculturalidad dentro de este organizador es el de crear espacios para la comunicación intercultural, lugares para la conversación entre personas de diferentes culturas, explicitando temas en los que se plasma la diferencia cultural.

\section{Abrir el contexto de referencia en vez de cerrarlo, la significación de lo local se encuentra enlo global}

\section{Formación en contextos de interculturalidad}

El espacio constituye un factor de estructuración simbólica de la personalidad social (Quellet, F., 1988). Corregir la referencia espacial y ampliarla tiene serias dificultades, porque el referencial no se elige desde la iniciativa del individuo particular, sino que se ha ido decantando históricamente, está entremetido en el material simbólico que se transmite por la cultura, ha configurado y ordenado la memoria colectiva y la interpretación del pasado; cambiarlo en los niños tiene dificultad porque fue soldándose con materiales de categorización emocional y cognitiva, por la misma vía por la que fue cobrando identidad personal y calibrando la identidad de los más afines; cambiarlo en los adultos es cambiar el sistema simbólico de la colectividad. Cambiar el referencial espacial y el grado de reconocimiento respecto a "los de aquí y los que vienen", son dos cambios que se producen al unísono, no se produce el uno sin el otro.

Solemos decir que el conocimiento reflexivo del mundo debe partir desde el entorno próximo y ampliarse hacia territorios concéntricos cada vez más amplios (Citron, S., 1987). Pero, aquello que se identifica dentro del círculo de proximidad ya sesga la dirección y altera el paso hacia los objetivos mayores. ¿Qué grado de cercanía tiene en cada caso, la diferencia cultural, la heterogeneidad? ¿Qué es próximo o distante? ¿Quién es más próximo que cualquier otro? Y, si los medios de comunicación de masas meten el mundo, y las diferencias comunitarias, en la sala de estar ¿Quién y qué está más cerca de qué y de quién?

Paul Henri Spaak, uno de los estadistas fundadores de la $\mathrm{CE}$, comentaba a los socialistas belgas: "hay un desfase entre lo que decimos y lo que hacemos. Ese es el fondo del problema. Debemos reconsiderar las cosas y eliminar de nuestras doctrinas los elementos que los acontecimientos demuestren que son insostenibles" (Huizinga, J. H., 1961).

Las sociedades tradicionales, que sorprendieron a exploradores, conquistadores, misioneros y estudiosos europeos, interesaron ante todo por su extraña (inaceptable) organización social y por la 
aparente amoralidad (desmesura) en el comportamiento. De ahí que de la extrañeza se pasara con facilidad al calificativo de "salvaje", "pagano" o "primitivo", cuando, efectivamente lo que hacían, desde su diferencia, era plantear al observador dos problemas antropológicos no advertidos por el pensamiento dominante en la Cultura Occidental: el de la esencial pluralidad de la cultura y el del valor relativo de la identidad cultural. El corolario inmediato de esas dos cuestiones fue, y sigue siendo, el de que la aproximación entre identidades culturales, dependiendo del modo como se vivencia la identidad, presenta el riesgo de confrontación (Fernández Buey, 1995). Este modo de interpretar la diferencia debiera constituir una advertencia constante respecto a que el concepto de identidad cultural referido a un grupo puede ser fácilmente manipulado ideológicamente y justificar discriminaciones e insolidaridad.

\section{Diferencia entre el discurso de la etnicidad y el de la ciudadanía}

El discurso de la etnicidad siempre tiene una referencia territorial, más tarde o más pronto la saca a relucir. Es el de la "negritud" que termina por pedir un Estado negro dentro del Estado blanco, el que toma la referencia étnica como criterio para la demarcación territorial. A este respecto es significativo el contenido de una entrevista con Heribert Barrera (Vila, 2001), un nacionalista catalán. Lleva a cabo su análisis político desde la confrontación entre los puntos de vista de "un patriota espanyol" y un "patriota català". Desde ese punto de vista, "endurecer" las leyes de emigración debe consistir en hacerlas "restrictivas"20. Por una razón fundamental: la entrada de diferentes introduce factores de impurificación de la etnicidad. Al demostrarlo, los argumentos se inician en cuestiones lingüísticas, pero llegan más lejos. Los emigrantes (magrebíes) traen consigo diferencias de cultura, de religión, de patrimonio genético, etc. ${ }^{21}$; el riesgo de pérdida de identidad se ve como amenaza real, la única defensa para una lengua minoritaria, en esas condiciones, sería que "els parlants formen una comunitat tancada que evita tot intercanvi", si se globalizara no tiene nada que hacer. La restricción de inmigración se convierte en una cuestión vital. La otra cuestión esencial es la no aceptación del bilingüismo: "Qui acepta de manera definitiva el bilingüisme actual, de fet, es resigna a la desaparició del catalá i de la nació catalana tal com l'entenem ara"22.

Siempre levantará sospechas el planteamiento que pretenda banalizar o reducir el valor paramétrico de las diferencias, precisando que es la magnificación de la diferencia la que obliga a admitir la realidad de la pluralidad. Pareciera que al mismo tiempo se rebaja la exigencia de los Derechos Humanos respecto a los denominados Derechos Nacionales territoriales ${ }^{23}$. Esta visión de territorialidad y etnicidad tiende a rebajar las diferencias transversales de género, carácter sexual, gentes sin papeles..., en tanto que "distracciones"24, respecto al problema fundamental de la creencia en la existencia "d'una nació catalana”. De ahí lo esencial de la acción política para la supervivencia de la cultura catalana; es decir, la importancia de un programa político dentro de la territorialidad para la preservación de la etnicidad. Por esta vía, estimo, que se magnifican los caracteres del extraño y los riesgos de su presencia. La propia realidad social ha de someterse a este planteamiento político ${ }^{25}$. Esta es la vía por la cual impedir que se produzca una "globalización interna" del Estado regional, de las instituciones y de las personas. Actuar desde la realidad social de la pluralidad obliga a planteamientos de globalización interna. El nacionalismo se puede tomar como argumento defensivo de otro atrincheramiento con mayor extensión territorial: p. e. España y la unidad nacional. 
Europa ya es nombre común y desde enero del 2002 en todo el territorio circula la misma unidad monetaria (Barzini, 1984). Todos los europeos realizamos las operaciones de compra-venta en el mismo sistema de cambio. Cada vez es Europa más identificable (Defargues, M., 1983). El recorrido político cada vez avanza más. Junto a este trayecto político y económico ha de tener lugar otro más sinuoso e irregular de individuos y grupos que progresan en la identificación con Europa, en la comprensión de Europa y en la reorganización de los conceptos de propio y extraño. El problema de la Unión Europea pertenece a la categoría política y económica, los de la identificación, compresión y reconstrucción de identidad cultural, constituye un gigantesco problema pedagógico. Porque en la Unidad Europea ha de cambiar la referencia territorial de costumbre $\mathrm{y}$, sin embargo, no tenemos un imaginario territorial común, no tenemos una lengua común, no tenemos una religión común... Por lo tanto, la unidad hay que construirla desde el punto de vista de la ciudadanía.

El riesgo actual es el de confrontar un nacionalismo con otro nacionalismo. Desde un punto de vista pedagógico este es el problema que, en los planes de formación, han de asumir las Humanidades.

Por lo general el extremo de la exclusividad en la identificación regional (el independentista) es quien posee mayor grado de frustación (menos estima, satisfacción y "bienvaillance") con respecto a su región y a su país ${ }^{26}$. Y, cuanto mayor sea el conflicto percibido entre identidades en el mismo territorio, menor es la identificación con todo lo que no sea el propio grupo (endogrupo o grupo regional y exogrupo o gruponación), menos positivas las emociones que se asocian a la percepción de las otras escalas de grupo, y menor es la atribución de valores a las mismas ${ }^{27}$.

Lo que evidencia la importancia de acciones de formación que fomenten la tolerancia de espíritu, la sensibilidad por la diferencia, la comunicación intercultural, la reconstrucción de la memoria colectiva que se transmite a las nuevas generaciones, la modificación de los ejes en torno a los cuales concéntricamente se promueve la identidad histórica y cultural, el ensanchamiento de los horizontes en el patrón cultural de referencia... La dificultad, p.e. de la unión Europea se condensa en la conjunción de dos lemas diferentes de dos países miembros de la Comunidad . El de Bélgica que proclama: "la unión hace la fuerza"; y el de Luxemburgo: "queremos seguir siendo lo que somos".

\section{Criterios pedagógicos para la animación de la educación intercultural}

La historia y la experiencia demuestra que al menos las diferencias raciales, las diferencias lingüísticas y las religiosas encuentran muy complicado compartir un espacio común o luchar por los mismos proyectos institucionales. La mera interdependencia económica no garantiza la unidad política, menos aún la unidad de proyecto social; antes de que estallara la guerra de 1914 la interdependencia económica entre Alemania, Rusia y Francia era evidente. Ejemplos de las dificultades convivenciales en la Europa geográfica son los de Yugoslavia, Líbano, Chipre, Irlanda, Bélgica, ...etc. La evidencia contraria de convivencia entre comunidades de idiomas diferentes y distintas confesiones es la próspera Suiza; pero, desde la unión en 1291 de los tres primeros cantones, hasta que se unió Ginebra en 1814, pasaron 500 años y la historia convivencial lleva dos siglos.

La caída, hoy, de las fronteras políticas de antes nos lleva a la adventencia de que existen no menos sólidos y múltiples límites que se entrecruzan y obligan a la configuración de mapas diferentes para objetos diferentes en la consideración; es lo que Todd denomina "zócalos antropológicos” (Todd, E., 1990). La autonomía de las 
regiones actúa igualmente como elemento revisionista de los elementos identificadores de la nacionalidad y del internacionalismo comunitario.

La pluralidad es el atributo de sistemas culturales interpenetrados en los mismos espacios culturales, todos ellos celosos de sus rasgos de identidad y defensores activos de la originalidad (de lengua, de religión, de tradición, de arte...) de sus modos de vida. Tal interpenetración entre sistemas culturales se puede experimentar en forma conflictual; cuanto mayor es la presión de culturas externas más se vive como vaciamiento, es el modo de vivenciar el derecho a la diferencia. El conflicto se produce porque todo sistema cultural acaricia en algún momento o lugar la posibilidad de constituirse en eje de dominancia y de tolerancia: las minorías se absorben y desdibujan o quedan sometidas las diferentes comunidades a un sistema de relación claramente de dominante a dominado.

La existencia de estos modelos, y el papel que juega en ellos el modo de representación de las relaciones interculturales, obliga a pensar que, en la formación de los agentes educativos deben ocupar un lugar estas previsiones; junto a la meta de buscar un pluralismo de igualdad en la diferencia. Este modelo es de equilibrio muy delicado, las confrontaciones son conscientes y se plantean descubiertamente; queda absolutamente en las manos de los hombres libres hacer aflorar la paz. El enemigo fundamental es el de proponer en un territorio una identidad canónica; en función de la cual los rasgos diferenciales son rasgos menores cuya adhesión ha de ser superficial y periférica.

En los contenidos culturales de la formación es preciso introducir el criterio de la maximación de las semejanzas y la minimización de las diferencias, con el fin de que la diferencia en tanto que rasgo auténtico de identidad se transforme en motivación para nuevos e interesantes espacios comunicacionales entre individuos y grupos.
Estos criterios de movilización cultural afectan a la educación en su conjunto, tanto a los jóvenes como a los adultos. La educación de los adultos, además de intentar remediar las carencias culturales de carácter instrumental u ocupacional, deben atacar al corazón mismo de la limitación cultural y formativa: el anquilosamiento simbólico y el aislamiento comunicacional. El hombre más sensible culturalmente es un hombre que entre sus aspiraciones más arraigadas alimenta el deseo de salir y tomar contacto, encontrarse viviendo en otras comunidades de otros espacios, sentirse ser lejos de cuanto le está habitualmente modulando, asumiendo como elemento personal la teoría y la identidad del otro.

La formación básica de los individuos en contextos interculturales ha de ser cardinalmente comunicacional y reflexiva sobre el proceso que evite la transformación de la diferencia en desigualdad y poder acercarse al ideal del "mutuo reconocimiento".

Los diseños formativos, propuestos por documentos de política cultural o propuestos por iniciativas pedagógicas suelen intentar cumplir con el doble objetivo de alimentar la versión de identidad regional y la versión pluralista. Por lo general, los documentos autonomistas suelen decantarse por la primera, por un "empezar por ahî". La cuestión es que parece que estamos ante dos opciones diferentes: llegar a la identidad desde el reconocimiento de la pluralidad o reconocer la pluralidad desde la particularidad identitaria. Dilucidar entre estas estrategias supone en los formadores haber recorrido un itinerario ideológico respecto al problema de la interpretación del pluralismo. En nuestro contexto se expresa en la forma de partidos políticos autonomistas y partidos políticos nacionalistas. Ambas posiciones partidarias tienen el riesgo del exceso y la polarización en la resolución del dilema anterior.

Para no entrar en cuestiones de programas políticos acerca del tratamiento institucional de la pluralidad y de la "normalización" de la particularidad identitaria, 
indicaremos únicamente diferentes opciones ante los que puede quedar confrontado el proceso de formación (García CastañoPulido-Montes, 1999). Otros autores prefieren hablar de "modelos" de educación intercultural. En cualquiera de los casos no se trata únicamente de contenidos, supone la construcción general de un contexto de formación que se fundamenta en el implícito de cuanto se entiende acerca de la interculturalidad y del proceso cultural a seguir por parte de quien entra a formar parte de una comunidad cultural diferente o tiene que actuar como educador en contextos culturales plurales, especialmente en aquellos en los que se da el caso de un planteamiento cultural dominante.

El primer modelo se construye desde la necesidad de la "asimilación", cultura que debe ser incorporado y sujeto que debe incorporarse a la cultura; de lo contrario, se piensa, ni alcanzará igualdad de oportunidades ni conseguirá el umbral de utilidad social en el nuevo contexto. Porque se supone que la integración no se alcanzará fuera de niveles altos de "normalización" y de "homogeneización cultural". Se aplica, implícitamente, el concepto de "cultura dominante", bajo el criterio de que la homogeneización es el recurso principal de preservación de la cultura del territorio huésped.

Frente a este modelo hay un contenido de la formación intercultural que debe proponerse con el objeto de alcanzar una mentalidad pluralista y abierta: la expansión global de mecanismos de erosión cultural que algunos autores califican de etnocidio cultural generalizado. Entres ellos se identifica, sobre todo, el comercio globalizado y la expansión planetaria de industrias culturales, cuya propiedad se encuentra en los espacios culturales económicamente dominantes. Este aspecto no se cubre en la formación si no se introduce una segunda perspectiva. (ii) La segunda perspectiva sería, entonces, la de formar en la interculturalidad desde el reconocimiento de las diferencias culturales. Aquí el objetivo es el de mostrar el carácter multiétnico de la sociedad, por suponer que sin ese conocimiento no es posible la generación de actitudes pluralistas. Aquí el problema es dónde colocar cuantitativamente el límite de las culturas consideradas.

(iii) Cabe un tercer modelo, cuyo objetivo es precisamente extender la mentalidad pluralista, en tanto que actitud de respuesta al hecho plural. El foco se centra en alimentar un modo de posicionarse frente a la diferencia y a la propia referencia; es una actitud que alimenta como propia identidad la de vivir en y con un mundo plural. Para quienes la identidad tiene una clara referencia étnica dentro de un entorno de diferencia, se plantea como biculturalismo. Pero creo, que se trata de una salida de mínimos, que copia la actitud cultural del hecho de poder hablar una o más lenguas. Ciertamente este es un modelo en algunas regiones.

(iv) El nivel mínimo lo situaría en el fomento de la una educación antirracista.

El proyecto de formación de base, el humanismo fundamental, la verdadera animación de la condición humana, la calidad fundamental del clima para la formación no puede ser otro que el de la capacidad y la competencia de dialogar. La verdadera marca de originalidad de nuestra especie es la de ser capaces de resolver nuestros problemas dialogando. Aterrorizar ha de ser el único sistema de comunicación que todos, en todos los lugares y circunstancias nos hemos de prohibir y siempre nos hemos de negar a comprender. Este es nuestro primer principio de responsabilidad comunicacional. 


\section{Notas}

1. El art.1 de LOGSE (Ley $1 / 1990$ de 3 de Octubre - BOE de 4 de Octubre de 1990) hace referencia a los fines generales de la formación y expresa con tal la" formación en el respeto a la pluralidad lingüística y cultural de España.

2. Citado por Ortega, P.-Minguez, R.-Gil, R., p. 7. 1996.

3. Gerbert, P. La Construction de l'Europe. I. National, Paris. 1983.

4. Ad, II,5,13: "Cultura ánimi philosophia est". Un excelente resumen de la evolución del concepto es el de SOBREVILLA, D. Idea e Historia de la Filosofía de la Cultura en Europa e Iberoamérica. Un esbozo. En Id. Editor: "Filosogía de la Cultura". Ed. Trotta-CSIC. Valladolid, pp. 37-53. 1998 .

5. En su obra "De disciplinis", en la parte segunda denominada "De tradendis disciplinis", se aproximan los sentidos de "cultus animi" y el de "animam formare". El hecho de haber convertido este tema en objeto de tal tratado llevó a Ortega y Gasset a considerarlo como el primer estudio occidental sobre la cultura.

6. Cole, M. Psicología cultural. Morata. Madrid, p. 26. 1999.

7. Voltaire. Ensayo sobre la poesía épica y el gusto de los pueblos. C. Ibérica de publicaciones. Madrid. Los nombres completos de los autores referidos en el texto son: François-Marie Arouet (Voltaire), Charles Louis Secondat, Baron de Brède y de Montesquieu (Montesquieu) y Anne Robert Jacques Turgot (Turgot). 1930.

8. Herder, J. G. Herder y su ideal de Humanidad. Ed. La Lectura. Madrid. 1930.

9. P.e "Civilización" para elementos objetivos como la arquitectura y las tecnologías, "ciencias nomotéticas" o sobre leyes naturales y "ciencias idiográficas" o sobre conocimientos determinados por la Historia. etc.

10. Tylor, E.B. La ciencia de la cultura. En Kahn, J.S. 1875. El concepto de cultura: Textos fundamentales. Anagrama. Barcelona, pp. 9-29. Aunque el autor define de manera tan amplia el concepto de cultura, sus investigaciones recayeron de manera preferente sobre el estudio de las religiones. 1871 .
11. García-Carrasco, J.- García del Dujo, A. Teoría de la Educación II. Procesos primarios de formación del pensamiento y la acción. Ed. Univ. Salamanca, cap. X. 2001.

12. Brunner, J. La educación, puerta de la cultura. Visor. Madrid, p. 21. 1999.

13. En la opinión de Javier Echeverría (1999, p. 48) esta revolución se encuentra asociada al desarrollo de varias tecnologías, entre ellas: teléfono, radio, televisión, redes telemáticas, multimedia, hipertexto. El autor añade el teledinero, pero en este caso no se trata de tecnología sino de información económica circulante por una red telemática, podría ser perfectamente una novela.

14. Junto a términos como "mulato", "criollo", "mezcla de sangre".

15. "Que la variedad y no la uniformidad, el discrepar y no la uniformidad, el cambiar y no el inmovilismo, sean "cosas buenas", estas son las creencias de valor que emergen con la tolerancia, que se adscriben al contexto cultural del pluralismo y que tiene que expresar una cultura pluralista que haga honor a su nombre. Y estas son las premisas a partir de las que debemos valorar el llamado 'multiculturalismo' de nuestros días”. Sartori, G. o.c., p. 32. Cuando de los principios pasa el autor a las acciones concretas, a los criterios que pueden inspirar "leyes para extranjeros", las diferencias con él aumentan. 2001.

16. Según el lenguaje coloquial as emociones parece que proporcionan como decía Freud,"tonalidad afectiva". Maturana opina que la emoción es el instrumento mediante el que especificamos diferentes campos de acciones. Las emociones se distinguen unas de otras precisamente porque especifican distintos dominios de acciones. Maturana, H., p. 23. 1995.

17. Shazer, S. Desde algún punto de vista, todo el psicoanálisis es un intento interpretativo para encontrar la verdad de un padecimiento a partir de tres tipos de narraciones: (a) historias que la gente cuenta cuando está en estado de vigilia, (b) historias contadas cuando se encuentran en trance (hipnosis), (c) historias sobre sueños o historias sobre historias que ocurrieron cuando estaba el narrador dormido. Cfr. p. 14. 1999.

18. “...ese sentimiento que significa que la derrota definitiva del racismo se convierta en una política de Estado, en una política educativa, 
en un sentimiento de toda la sociedad mexicana”. Entrevista de Gabriel García MárquezRoberto Pombo al Subcomandante Marcos (El País, 25-III-2001).

19. "En los ejércitos de antes, el militar aprovechaba el tiempo para limpiar su arma y rehacerse de parque. En este caso, como nuestras armas son las palabras, tenemos que estar pendientes de nuestro arsenal a cada momento" (Id.id.).

20. "Jo no sé si hi ha una intenció deliberada. Peró és evident que qualsevol que vulgui espanyolitzar Catalunya té interés que la immigració vingui cap aquí. Es una fórmula molt eficaç". Vila, p. 94. 2001.

21. "No pretenc que un país hagi tenir una raça pura, aixó és una abstracció. Però hi ha una distribució genética en la població catalana que estadísticament és diferent a la de la població subsahariana, per exemple. Encara que no sigui políticament correcte dir-ho hi ha moltes característiques de la persona que vénen determinades genéticament, $y$ probablement la intel-ligência n'es una...”. (Vila, 2001 p. 96).

22. Vila, p. 174. 2001.

23. Vila, p. 107. 2001.

24. "Les esquerres en general tienen una posició demagógica que consisteix a escoltar les minories actives". (Vila, p. 93. 2001.

25. “en certa manera la societat civil és un mite”...de vagades es vol donar a la societat civil un paper excessiu" (Vila, 2001. p. 84).

26. Valencia J.F. (editor). Las imágenes de Europa en los europeos (Publicaciones del Departamento de Psicología Social de la Universidad del País Vasco), $n^{\circ} 5$. Se reúnen diversos trabajos de investigación aplicando escalas de Likert y se demuestra la posibilidad de manipulación experimental de las representaciones sociales (1991). Di-Giacomo, J.P., L'Europe vue par des étudiants Français, o.c., p. 16. La Revue internationale des sciences sociales (1982) Vol XXXIV, $\mathrm{n}^{\circ}$ 1, presenta toda una serie de trabajos bajo el lema: Images de la société mondiale. Nouveaux paradigmes et praxis planétaires (UNESCO, Paris), 1982.

27. Giovannini, D.-Cerrato, J., en Valencia, J.F. editor, o.c. p. 24.

\section{Referencias bibliográficas}

Arent, H. La condición humana. Paidos. Barcelona. 1996 v.o. 1956.

Austin, J.L. Palabras y acciones. Paidos. Buenos Aires. 1971 v.o. 1962.

Barzini, L. Les européens. Ed. BouchetChastel, Paris. 1984.

Blackmore, S. La máquina de los memes. Paidós, Barcelona. 2000.

Bonniol, J.L. La couleur comme maléfice: une illustration créole de la géneéalogie del Blancs et des Noires, Aalbin Michel, Paris. 1992.

Bruner, J. La educación, puerta de la cultura.Visor. Madrid. 1999.

Bruner, J.-Weiser, S. La invención del Yo: la autobiografia y sus formas. En Olson, D.R.-Torrance, N., "Cultura escrita y oralidad”. Gedisa. Barcelona. 1998.

Citron, S. Le mythe national. Ed. Ouvrières, Paris. 1987.

Claxton, R. Vivir y aprender. Alianza, Madrid. 1987.

Defargues, M. L'Europe et son identité dans lo monde. Ed. STH, París. 1983.

De Vega, M. Introducción a la psicología cognitiva. Alianza, Madrid. 1984.

Echeverría, J. Los señores del aire: telépolis y el tercer entorno. Destino. Barcelona. 1999.

Eiser, J. Richard. Psicología social. Actitudes, cognición y conducta social. Pirámide, Madrid. 1989.

Fernández Buey, F. La barbarie, de ellos y de los nuestros. Paidos, Barcelona. 1995. 
Ferrater, Mora, J. art. Tabla. En Diccionario de Filosofía. Alianza Diccionarios, Madrid, T. 4. 1979.

Frisch, K.von La vida de las abejas. Labor, Barcelona. 1994 v.o. 1927.

García Carrasco, J.-García del Dujo, A. Teoría de la Educación .T.II. Procesos primarios de formación del pensamiento y de la acción. Ediciones Universidad de Salamanca, Salamanca. 2001.

García Castaño, F.-Pulido, R.A.-Montes, A. Educación multicultural y el concepto de cultura. En García Castaño, FGRANADOS, Eds. 1999. Lecturas para educación intercultural. Trotta, Madrid. 1999.

Gazzaniga, M. El pasado de la mente.Ed. Andrés Bello, Barcelona. 1999.

Glissant, E. Introduction à une poétique du divers. Paris, Gallimard. 1954.

Huizinga, J.H. Mr. Europe: A political biography of Paul Henri Spaak. Weidenfeld-Nicolson,Londres. 1961.

Holton. La imaginación en la ciencia. En Preta, L. Comp. O.c. 1993.

Jodelet, D. La representación social: fenómenos, concepto y teoría, en S. Moscovici, Psicología Social, t. II. Pensamiento y vida social.Psicología social y problemas sociales. p. 474. 1986.

Laplantine, F. Le métissage. Un exposé pour comprendre. Un essai pour réfléchir. Flammarion-Dominos, Evreux. 1997.

Magris, Cl. Métissages. L'Harmattan, París. 2 Vol. 1992.

Maturana, H. La realidad iobjetiva o construida?. T. I. Fundamentos bio- lógicos de la realidad. Anthropos, Barcelona. 1995.

Kelly, G. The psychology of personal constructs, 2 vol.Norton, Nueva York. 1963.

Olson, D.R. El mundo sobre el papel. El impacto de la escritura y la lectura en la estructura del conocimiento. Gedisa, Barcelona. 1998.

Ortega P.-Minguez, R.-Gil, R. Valores y eduación. Ariel, Barcelona. 1996.

Popper, K. La sociedad abierta y sus enemigos. Paidos, Barcelona. 1982.

Preta, L. Imágenes y metáforas en la ciencia. Alianza, Madrid. 1993.

Quellet, F. Pluralisme et école. Jalons pour une approche critique de la formation interculturelle des éducateurs. Inst. Québécois de R. sur la C., Québec. Ed. 1988.

Rosa, A.-Bellelli, G.-Bakhurst, D. Representaciones del pasado, cultura personal e identidad nacional. En Id.id. (Eds.) Memoria colectiva e identidad nacional. Biblioteca Nueva, Madrid. 2000.

Ross, W. Nuestro imaginario cultural. Simbólica literaria hispanoamericana. Paidos, Barcelona. 1992.

Sartori, G. La sociedad multiétnica. Pluralismo, multiculturalismo y extranjeros. Taurus, Madrid. 2001.

Shazer, S. En un origen las palabras eran magia. Gedisa, Barcelona. 1999.

Todd, E. L'invention de l'Europe. Ed. du Seuil, Paris. 1990.

Tugendhat, Ch. El sentido de Europa Alianza, Madrid. 1987.

Vila, E. ¿Qué pensa Heribert Barrera?, Proa Deria, Barcelona. 2001. 
